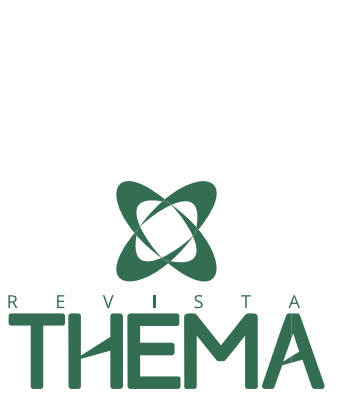

\title{
Um Estado da Arte sobre os aspectos subjetivos nas pesquisas em Educação Matemática
}

\section{State-of-the-art about the subjective aspects of research in Mathematics Education}

Letícia de Queiroz Maffei ${ }^{1}$; João Alberto da Silva ${ }^{1}$

\section{RESUMO}

Este artigo se caracteriza como um estudo de Estado da Arte que procura a compreensão de como a comunidade brasileira de pesquisadores em Educação Matemática tem discutido e abordado os aspectos subjetivos da/na relação com esta área do conhecimento. O corpus de análise considerado neste estudo são publicações realizadas, no período entre 2006 e 2015, nos anais do Encontro Nacional de Educação Matemática (ENEM) e do Seminário Internacional de Pesquisa em Educação Matemática (SIPEM), bem como na revista BOLEMA (Boletim de Educação Matemática). A pesquisa permitiu que emergissem três eixos temáticos nos quais se distribuíram os estudos: ser professor, vínculos com a Matemática e escritas de si. Eixos que conforme foram sendo explorados mostraram-se atravessados pela subjetividade e com fortes conexões.

Palavras-chave: Subjetividade, Estado da Arte, Educação Matemática.

\begin{abstract}
This paper presents a study of the state-of-the-art on how the Brazilian community of researchers in Mathematics Education have discussed and addressed the subjective aspects of their field. The corpus analysed in this work is composed of proceedings from 2006 to 2015 of the 'Encontro Nacional de Educação Matemática' (ENEM) and of the 'Seminário Internacional de Pesquisa em Educação Matemática' (SIPEM), as well as publications from the journal BOLEMA ('Boletim de Educação Matemática'). Our research found three thematical axes of study: what means to be a professor, what are the ties of the researchers with Mathematics and what the researchers write about themselves. The exploration of these three aspects has shown that they are strongly correlated and influenced by subjectivity.
\end{abstract}

Keywords: Subjectivity, State-of-the-art, Mathematics Education.

\footnotetext{
${ }^{1}$ FURG - Universidade Federal do Rio Grande - Rio Grande/RS - Brasil.
} 


\section{CONSIDERAÇÕES PRELIMINARES}

Este é um estudo de Estado da Arte (FERREIRA, 2002) que procurou compreender como a comunidade brasileira de pesquisadores em Educação Matemática tem discutido e abordado os aspectos subjetivos da/na relação com esta área do conhecimento. Subjetivo, do latim subjectivus, refere-se ao que é relativo ao sujeito, individual, pessoal (CUNHA, 2010). Mas em que os aspectos subjetivos se relacionam com uma ciência dita exata, como é o caso da Matemática?

Não raramente, quando não sabemos ao certo o que responder, ou como lidar com alguma situação, respondemos: "Ah! É muito subjetivo!", ou seja, subjetividade é recurso de justificativa que se confunde entre o clichê e o tabu. Falar de subjetividade, pensar em subjetividade, é também compreender que estão sendo feitas escolhas com base em uma avaliação particular e individual. Ao considerar o "eu" pesquisador enquanto sujeito definimos o que pode ou não ser compreendido dentro deste universo que estabelecemos, ou pensando pelo viés da fenomenologia: nossa percepção, aquilo que constatamos. Resgatamos aqui a fenomenologia, pois o estudo aqui apresentado é um recorte de uma pesquisa de doutorado realizada sob uma perspectiva fenomenológica. Na pesquisa buscamos compreender como se mostram os afetos em relação à Matemática na escrita de pedagogas em formação em um curso de Pedagogia de uma Universidade do sul do estado do Rio Grande do Sul. Porém, neste artigo nos debruçaremos sobre o Estado da Arte realizado em torno da subjetividade, concebendo os afetos dos quais nosso estudo trata como pertencentes ao âmbito da mesma.

Fenomenologia é um vocábulo composto por fenômeno + logos. Nesse sentido, compreende-se fenômeno como "tudo aquilo que é percebido pelos sentidos ou pela consciência" (CUNHA, 2010, p. 289) ou como definiria Bicudo (2010), aquilo que se mostra, o que aparece. E logos, termo grego referente à "palavra, estudo, tratado" (CUNHA, 2010, p. 393), ou ainda, "pensamento, reflexão, reunião, articulação" (BICUDO, 2010, p.29). Logo compreender a fenomenologia é "como a articulação do sentido do que se mostra, ou como reflexão sobre o que se mostra" (BICUDO, 2010, p. 29).

A explicação do que vem a ser fenomenologia, em termos etimológicos, passa uma ideia incipiente, porém Bicudo (2010, p. 29) destaca que pode se mostrar "complexa se perguntarmos: o que se mostra e como se mostra isso que se mostra? A quem se mostra? Onde se mostra o que se mostra?". No caso deste estudo procuramos verificar o que se mostra quando buscamos por aspectos subjetivos em pesquisas brasileiras no âmbito da Educação Matemática que foram apresentadas nos últimos dez anos no periódico Bolema e nos eventos vinculados à Sociedade Brasileira de Educação Matemática, o SIPEM e o ENEM.

Continuemos aqui com a escrita no intuito de apresentar o que se mostra inicialmente e o que pretendemos buscar com o estudo: pensar a Matemática para além de conteúdos, metodologias de ensino e permitir um olhar para aspectos como afetos, percepções, motivações, escolhas, crenças. Enquanto professores de Matemática somos atravessados por situações nas quais a subjetividade é evidente: Não gosto de Matemática! Gosto da professora tal, mas não gosto muito do conteúdo! Medo da prova! Escolhi ser professor pela paixão e por acreditar na Educação!, mas como sentimos esses afetos, ou ainda, pensamos sobre isso ao ensinar?

O movimento do pensar fenomenológico nos coloca em uma trajetória "que nos faz avançar em termos de compreensão do realizado e de quem efetua o realizado, isto é, do que fazemos e de nós 
mesmos como seres humanos individuais e como seres que produzem cultura e constroem/criam a realidade mundana" (BICUDO, 2010, p. 28). É ao longo dos passos desta trajetória de busca da compreensão do realizado e de quem somos nós enquanto educadores matemáticos e pesquisadores que se constitui esta pesquisa que interroga sobre as subjetividades dos estudos alheios, quiçá por intenção de compreender aspectos subjetivos que levaram a escolhas de carreira, afetos e desafetos pela Matemática ou até mesmo pelo ser professor.

Se estamos conduzindo uma pesquisa no sentido de perceber o que se mostra, não seria necessário esclarecer que muito do que irá se estabelecendo nesta escrita foi se constituindo ao longo do próprio estudo sem que houvessem categorias ou concepções dadas a priori. Assim, partimos da necessidade de buscar o que se mostra em relação à subjetividade e a importância dada a ela, mas estamos diante de um caminho que se apresenta e prolonga conforme o trilhamos. A próxima seção apresentará, como já referido anteriormente, detalhamentos sobre o modo e os critérios utilizados para conduzir este Estado da Arte.

\section{DELINEAMENTO METODOLÓGICO}

Esse estudo trata-se de uma pesquisa qualitativa (BOGDAN; BIKLEN, 1994; GIL, 2010) que segue o delineamento de um Estado da Arte (FERREIRA, 2002). Essa modalidade de pesquisa configura-se como um estudo bibliográfico inventariante, que se debruça sobre um corpus de análise definido. Ferreira (2002) destaca que tais pesquisas trazem em comum o desafio de mapear e discutir certas produções acadêmicas em distintos campos do conhecimento, tentando responder que aspectos e dimensões são privilegiados em diferentes épocas e lugares. Buscamos mapear também de que formas e em que condições têm sido produzidas dissertações, teses, publicações em periódicos e comunicações em anais de eventos.

Para fins de circunscrever um campo de análise de nosso estudo tomamos por referência a Sociedade Brasileira de Educação Matemática (SBEM). A escolha se deve por ser a associação que reúne os pesquisadores da área, congregando profissionais da Educação Matemática que se destacam pela sua expressividade, bem como tem se configurado como um dos locus mais profícuos de discussão da área.

Para composição do corpus de análise serão considerados os eventos cujos anais estão disponibilizados no site da SBEM, são eles: Encontro Nacional de Educação Matemática (ENEM) e Seminário Internacional de Pesquisa em Educação Matemática (SIPEM). O periódico analisado será a revista BOLEMA (Boletim de Educação Matemática), pois é uma das mais antigas publicações na área da Educação Matemática no país e tem sido avaliado como Qualis A1 pela CAPES na área de Ensino de Ciências e de Educação.

Para a seleção dos materiais determinamos como período de análise as publicações realizadas entre 2006 e 2015. Em relação aos eventos escolhidos serão consideradas as três últimas edições de ambos: ENEM - 2007, 2010 e 2013 - e SIPEM -2009, 2012 e 2015. De acordo com o período determinado, 2006 até 2015, deveríamos incluir a edição de 2006 do SIPEM, porém, não se torna viável devido ao fato de que o material disponibilizado está com uma qualidade baixa e ausência de algumas páginas, o que prejudica a leitura do documento. Todavia, o período de tempo escolhido será devidamente contemplado através da análise dos artigos publicados no periódico BOLEMA entre os anos de 2006 e 2015. 
Considerando as edições de eventos supracitadas e o período de tempo determinado, coletamos todos os títulos de comunicações científicas apresentadas nos anais do ENEM, todos os títulos de artigos presentes nos anais do SIPEM e todos os títulos de artigos das edições de BOLEMA. Analisamos um total de 2.573 trabalhos cuja triagem foi realizada em três etapas: primeiramente por títulos, seguida de uma segunda triagem por títulos refinando um pouco mais o enfoque e finalmente, através da leitura dos resumos para verificar aqueles trabalhos cujos títulos eram inconclusivos diante do enfoque escolhido.

Assim, esse corpus de análise foi interpretado tendo a seguinte interrogação tomada como ponto de partida: Como a comunidade brasileira de pesquisadores em Educação Matemática tem discutido e abordado os aspectos subjetivos da/na relação com esta área de conhecimento? Nessa busca, entendemos subjetivo como aspectos relacionados ao sujeito, as questões pessoais, afetos e julgamentos. Assim, foram selecionados trabalhos nos quais se mostrou presente a posição dos sujeitos principalmente no que diz respeito às sensações e julgamentos diante da Matemática. O número de trabalhos considerados em cada etapa e as fontes nas quais foram localizados está ilustrado na tabela 1.

Tabela 1. Trabalhos considerados em cada etapa da pesquisa

\begin{tabular}{|c|c|c|c|c|}
\hline & TOTAL & $1^{\text {a }}$ Triagem & $2^{\text {a }}$ Triagem & Triagem Fin \\
\hline ENEM & 1.598 & 479 & 257 & 97 \\
\hline IX ENEM - 2007 - Comunicações Científic & 279 & 82 & 39 & 13 \\
\hline X ENEM - 2010 - Comunicações Orais & 550 & 203 & 118 & 34 \\
\hline XI ENEM - 2013 - Comunicações & 769 & 194 & 100 & 50 \\
\hline SIPEM & 520 & 255 & 153 & 38 \\
\hline IV SIPEM - 2009 & 202 & 92 & 55 & 13 \\
\hline V SIPEM - 2012 & 149 & 103 & 58 & 14 \\
\hline VI SIPEM - 2015 & 169 & 60 & 40 & 11 \\
\hline BOLEMA & 419 & 265 & 145 & 34 \\
\hline 2006 - v.19; n.25 e n.26 & 10 & 8 & 6 & 1 \\
\hline 2007 -v.20; n.27 e n.28 & 14 & 8 & 5 & 2 \\
\hline 2008 - v.21; n.29, n.30, n.31 e n.32 & 39 & 22 & 5 & 2 \\
\hline $2009-v .22 ; n .33$ e n.34 & 20 & 12 & 7 & - \\
\hline 2010 - v.23; n.35A, n.35B, n.36 e n.37 & 45 & 24 & 19 & 4 \\
\hline 2011 - v.24; n.38, n.39, n.40 e n.41 & 49 & 27 & 9 & - \\
\hline 2012 - v.26; n.42A, n.42B, n.43 e n.44 & 55 & 36 & 17 & 3 \\
\hline 2013 -v.27; n.45, n.46 e n.47 & 49 & 28 & 20 & - \\
\hline $2014-v .28 ;$ n. 48, n.49 e $n .50$ & 75 & 59 & 32 & 13 \\
\hline $2015-v .29 ;$ n. 51, n.52 e n.53 & 63 & 41 & 25 & 9 \\
\hline [Total de artigos em cada etapa] & [2.537] & [999] & [555] & [169] \\
\hline
\end{tabular}

Fonte: Elaborada pelos autores.

Diante da nossa interrogação inicial foram priorizados estudos que indicavam uma centralidade para aspectos subjetivos. Com a primeira triagem ainda se mantiveram títulos em que de alguma forma figuravam traços de subjetividade, porém com enfoque em materiais pedagógicos específicos, conteúdos, práticas específicas, relatos de experiências e não propriamente uma pesquisa com enfoque em aspectos da subjetividade. Na segunda triagem por títulos visamos estreitar mais esse enfoque, como referido anteriormente. A triagem final permitiu chegar a um número mais reduzido de textos os quais catalogamos levando também em consideração as palavras-chaves utilizadas pelos autores. 
Quanto à análise dos dados, durante a triagem dos textos percebemos que as palavras-chaves empregadas pelos autores nem sempre são muito expressivas das temáticas abordadas nas escritas. Além disso, os aspectos subjetivos, que são nosso foco de interesse, por vezes não são explicitados ou atingem grau de relevância a ponto de serem considerados palavras-chaves. Assim, nossa primeira análise se deu diretamente sobre termos empregados nos resumos dos trabalhos. Optamos por tal estratégia, pois

\begin{abstract}
O resumo permite outras descobertas, se lido e interrogado para além dele mesmo, numa prática de leitura mais "livre", aquela fora dos preceitos previstos pelo autor. Mas, ao mesmo tempo, a leitura de cada resumo é "freada" pelas pistas, indícios deixados nele pelo autor, que conduzem a uma e não outra compreensão de todo e qualquer resumo. Ainda, podemos dizer que a História de certa produção, a partir dos resumos das pesquisas, não oferece uma compreensão linear, uma organização lógica, seqüencial do conjunto de resumos. Entre os textos há lacunas, ambigüidades, singularidades, que são preenchidas pela leitura que o pesquisador faz deles. Então, a História da produção acadêmica é aquela proposta pelo pesquisador que lê. Haverá tantas Histórias quanto leitores houver dispostos a lê-las (FERREIRA, 2002, p.269).
\end{abstract}

No geral, temos uma pesquisa, palavras-chaves e com base nessas palavras vamos percorrendo bancos de dados a procura de produções que se enquadrem em nossas buscas, entretanto nesse estudo percorremos um caminho inverso. Em se tratando da 'subjetividade', não conseguimos preestabelecer palavras-chaves para conduzir esta pesquisa inicial. Além disso, nosso viés hermeneuta nos indica a deixar desvelar-se o que se mostra. Então fomos selecionando aquelas que se mostraram mais relevantes e presentes ao longo das leituras realizadas para as triagens e percebendo quais permitiam retornos a nossa interrogação inicial. Optamos por uma organização em eixos temáticos a fim de enfatizar a forte inter-relação existente e desencorajar qualquer tipo de categorização excludente que pudesse suprimir as conexões. Dessa primeira aproximação surgiram três eixos temáticos, que são: ser professor, vínculos com a Matemática e escritas de si.

Em um segundo momento, analisamos as palavras-chaves de cada um dos artigos, já as considerando dentro de cada um dos eixos temáticos emergentes. Essas palavras-chaves foram organizadas através do recurso das nuvens de palavras ${ }^{2}$, que é um recurso metodológico que permite evidenciar a pregnância das palavras ou expressões, já que o tamanho da fonte com a qual cada palavra é apresentada representa proporcionalmente a frequência com que elas aparecem no texto escolhido. Nesse caso a frequência representa o número de trabalhos nos quais estas palavras ou expressões foram localizadas.

$\mathrm{Na}$ apresentação da análise de dados explicitamos a que se refere cada um dos eixos temáticos e evidenciamos as nuvens de palavras que emergem do corpus de análise. Em seguida, apresentamos algumas referências de textos inventariados que sustentam nossas reflexões. A totalidade de trabalhos analisados e que se prestaram para a criação dos eixos temáticos e das nuvens de palavras encontra-se nos anexos desse artigo.

\footnotetext{
${ }^{2}$ As nuvens foram elaboradas em Word Tagul Clouds, site no qual pode ser realizado um acesso pessoal e serem digitadas palavras ou copiado algum texto e então definidas as configurações desejadas para a nuvem a ser criada. Disponível em: <https://tagul.com>. Acesso em: 05/11/2016.
} 


\section{RESULTADOS: APRESENTAÇÃO E DISCUSSÃO}

A análise por palavras-chaves permitiu constatar quais termos vêm sendo utilizados para enquadrar pesquisas que trazem uma abordagem que explora ou cruza pelo subjetivo. Embora o ser professor, os vínculos com a Matemática e as escritas de si tenham sido eixos que emergiram a partir da leitura dos resumos e que mantiveram representatividade, quando da análise diretamente nas palavras-chaves dos materiais selecionados, cabe destacar que com a leitura minuciosa dos resumos, realizando o garimpo pelos termos de interesse para a pesquisa, acabamos por reduzir nosso corpus de análise de um total de 169 artigos para o valor final de 115 artigos.

As palavras elencadas permitiram um panorama quanto ao enfoque dado no âmbito de cada uma das categorias estabelecidas. O ser professor (Fig. 1) emergiu mostrando-se relacionado às escolhas de carreira, identidade profissional, saberes docentes e aspectos vinculados à constituição profissional dos sujeitos. Embora tais características pareçam estar atreladas a questões formativas e de bases conceituais o que emerge da leitura dos artigos são fortes relações com crenças, concepções, histórias de vida que auxiliam não apenas na constituição do sujeito, mas também acabam por orientar suas escolhas e posturas.

\section{Saberes docentes

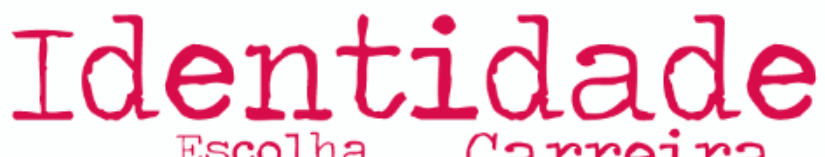 \\ Ser Professor}

Figura 1. Ser professor - palavras-chaves.

Fonte: Elaborada pelos autores.

Vínculos com a Matemática (Fig. 2) englobaram palavras que em vários momentos foram preponderantes na seleção dos resumos e remetem a sentimentos, sensações, julgamentos, crenças, como já explicamos ao apresentar o enfoque desta pesquisa. É neste rol que poderemos encontrar termos como motivação, criatividade, ansiedade, expectativas, dificuldades e emoções. Cabe destacar aqui que durante a leitura dos resumos emergiram palavras - como gostar, não gostar, medo, aversão, prazer, sentimento, desencanto, chatice - que acabaram não apresentando representatividade quando da análise das palavras-chaves, porém reforçam ainda mais a presença dos aspectos subjetivos nos estudos considerados.

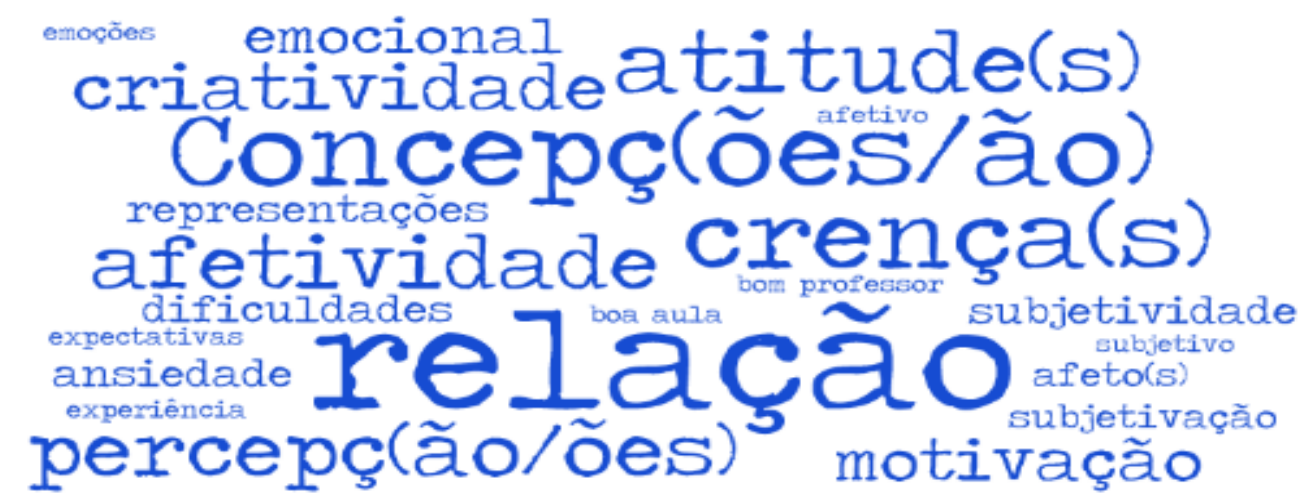

Figura 2. Vínculos com a Matemática - palavras-chaves

Fonte: Elaborada pelos autores. 
A denominação: Escritas de si (Fig. 3) emerge na intenção de abarcar processos de reflexão e escritas que resgatam memórias, histórias pessoais, trajetórias e percepções que são colocados como recursos no processo de produção das pesquisas e até mesmo constituição do sujeito. Elementos que por vezes são concebidos como metodologias de pesquisa e outras como importantes constituintes no processo de formação. Dentre os trabalhos analisados mostra-se a importância das escritas e do olhar para si como elementos reflexivos, propulsores de mudanças e agregadores de valores aos processos formativos, sejam eles em cursos de graduação ou em contextos de formação continuada.

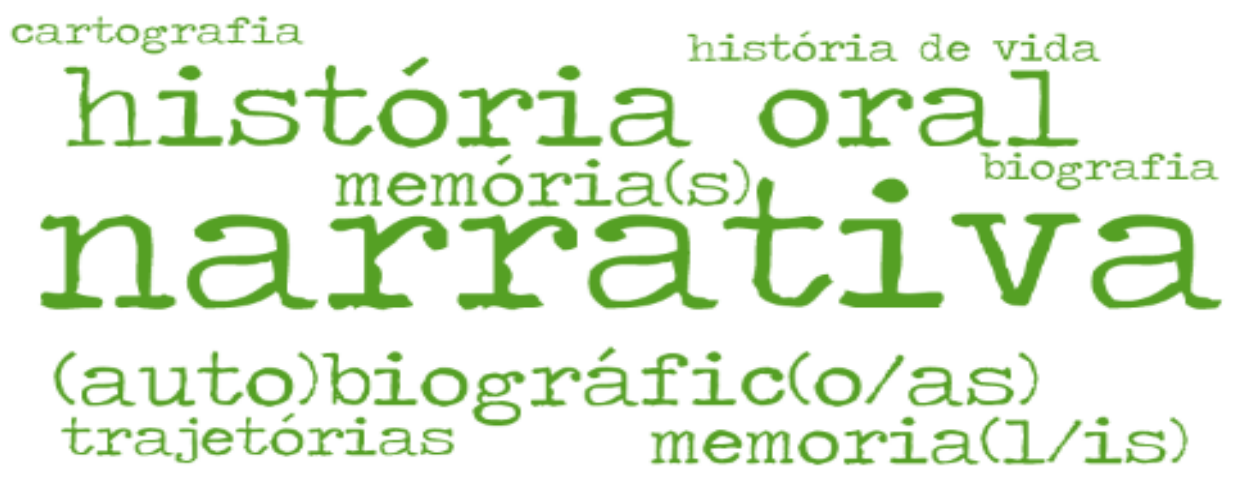

Figura 3. Escritas de si - palavras-chaves

Fonte: Elaborada pelos autores.

Embora na elaboração das nuvens tenhamos mantido a separação nos três eixos temáticos que emergiram diante das palavras encontradas, ao tratar dos estudos selecionados nem sempre conseguiremos manter esta divisão. Muitas vezes os vínculos com a Matemática, o ser professor e as escritas de si se mostraram de maneira complementar ou até mesmo interligada em alguns estudos. É o caso de estudos como o de Martins e Rocha (2013), que apoiadas no método (auto)biográfico, utilizando como principal instrumento de coleta e análise de dados o memorial de formação, buscaram investigar a percepção dos licenciandos em Matemática em relação a proposta de estágio e as contribuições para a constituição da identidade profissional docente.

No estudo em questão podemos perceber a presença de termos oriundos das três nuvens elaboradas: identidade vinculada ao ser professor; percepção, vínculo com o estágio em Matemática; (auto)biográfico e memorial, às escritas de si. Este entrelaçamento vai se mostrando presente também na análise de outros estudos. Assim, agruparemos e aproximaremos nesta escrita estudos que se conectem uns aos outros devido a algum dos termos destacados. Optaremos não somente por fazer esta aproximação utilizando um dos termos como elo de conexão, mas também resgataremos as outras possíveis aproximações em nossas considerações finais. Ao optar por privilegiar um dos termos para a conexão de ideias não estaremos deixando de apresentar os outros que emergirem juntamente na análise.

Tomemos a questão da constituição da identidade profissional docente que emerge nos estudos de Martins e Rocha (2013) como um processo contínuo e consideremos os estudos de Levy (2013) que resgatando tópicos da produção literária abordou os temas identidade docente e práticas de investigação. O foco da pesquisa foram docentes de Matemática em formação inicial, sendo defendida a ideia de que a constituição da identidade docente não se restringe a momentos posteriores à habilitação profissional de quem ensina. Para o pesquisador a identidade do docente de Matemática ainda que não se reduza a ação de ensinar, guarda estreito vínculo com a mesma. 
Buscando compreender a constituição da identidade do professor nos cursos de Licenciatura e explicitando o perfil esperado dos futuros professores, Paulo (2012) explorou as Diretrizes Curriculares Nacionais dos cursos de Licenciatura em Matemática, Química e Pedagogia. A pesquisadora destacou, diante da análise dos dados obtidos, a necessidade de considerar as ações da experiência vivida para compreender a constituição da identidade do professor.

Nacarato (2012) analisou como professores de Matemática em início de carreira constituem suas identidades profissionais, em pesquisa que utilizou como recursos metodológicos a entrevista narrativa e os grupos de discussão. A autora resgatou o caso de uma das professoras que ao ser levada a refletir sobre sua história de vida tomou consciência de suas experiências, autointerpretandose e projetando-se como uma professora que deseja que seus alunos aprendam a Matemática.

Resgatando a memória e as trajetórias escolares de alunos jovens universitários, Bernardo (2013) buscou compreender se as escolhas profissionais destes jovens tiveram influência da identidade profissional docente. A pesquisadora procurou identificar se a profissão docente era um objetivo para esses jovens e analisou por quais caminhos, para além da formação nas licenciaturas, a docência pode ser constituída.

A identidade foi abordada também em outros contextos para além da identidade docente, ou identidade profissional. Silva (2007) teve em vista a identidade cultural, apresentando um breve histórico envolvendo a História Oral para refletir sobre a formação do professor de Matemática. Frade e Rodrigues (2009) desenvolveram seus estudos com alunos de uma escola de Ensino Médio da rede de ensino público federal, com o objetivo de estudar as identidades matemáticas desses alunos, com ênfase nos sistemas de crenças em relação à Matemática.

Ao tratar das crenças em relação à Matemática podemos destacar o estudo de Zat (2013) que investigou a relação entre a formação acadêmica do professor e a construção de crenças e concepções que são evidenciadas na prática em sala de aula por professores de Matemática. Narrativas escritas e entrevistas orais mostraram que ainda que as marcas pessoais e a história de vida trazidas por cada uma das professoras sejam poderosas, a formação acadêmica reforça algumas concepções e/ou contribui com algumas mudanças.

Refletindo sobre a influência das crenças na formação matemática do pedagogo, bem como sua escolha pelo curso de Licenciatura em Pedagogia, Costa e Curi (2010) analisaram narrativas sobre experiências com a Matemática de licenciandos em Pedagogia. As pesquisadoras buscaram discutir novas formas de abordagem da Matemática de forma a minimizar os efeitos das crenças relativas à Matemática na prática pedagógica do futuro professor. Outro estudo em que tomou-se como base a narrativa de acadêmicas de um curso de Pedagogia foi o de Marquesin e Nacarato (2015) que buscou compreender quais crenças e concepções quanto à natureza da Matemática essas futuras professoras traziam consigo e eram (re)significadas no processo de formação inicial.

Silva e Santos-Wagner (2013) investigaram crenças, concepções, memórias de experiências com a Matemática e escolha profissional de licenciandos em Matemática. As pesquisadoras constataram que os estudantes apresentam indícios de mais de um tipo de visão sobre a Matemática. Tal variabilidade, na perspectiva delas, parece estar associada a experiências vivenciadas com familiares e exprofessores de Matemática, sendo estas experiências significativas não apenas para a elaboração de 
concepções sobre Matemática, ensino e aprendizagem, como também, para a escolha profissional destes estudantes.

Conceitos como criatividade também emergem em nossa busca, para tanto, destacamos o estudo de Gontijo (2010) que discutiu a concepção de criatividade em Matemática, ressaltando que um trabalho pedagógico organizado visando favorecer o desenvolvimento da criatividade pode colaborar para a superação da ansiedade envolvida na aprendizagem desta disciplina e quebrar barreiras que impedem o sucesso nessa área. O termo ansiedade pode ser destacado em outras pesquisas como a de Mendes e Carmo (2014) que identificaram atribuições e graus de ansiedade ante a Matemática em relatos de estudantes de duas turmas, uma de $2^{\circ}$ ano e outra de $6^{\circ}$ ano do Ensino Fundamental. Foi observado que as situações nas quais os alunos indicavam maior ansiedade foram aquelas passíveis de falha e de sofrer alguma forma de punição.

Reforçando situações nas quais os alunos indicam maior ansiedade, os estudos de Cruz e Neves (2010) destacarão que os estudantes com os quais realizaram a pesquisa avaliam a prova escrita de Matemática como sendo a que mais gera ansiedade. O estudo realizado buscou compreender como os estudantes do $9^{\circ}$ ano do Ensino Fundamental de uma escola pública percebem a Matemática, seu ensino e aprendizagem através da análise de suas falas em relação aos afetos, lembranças/sentimentos, atitudes, relação professor-aluno, fracasso e sucesso em Matemática. Os resultados da pesquisa revelaram a Matemática como sendo concebida a disciplina mais difícil por parte da maioria dos estudantes. Tais estudantes quando pensam ou lidam com a Matemática acabam por atrelar a ela sentimentos negativos - desânimo, desespero, tristeza ou angústia - e, como já referido anteriormente, avaliam a prova escrita de Matemática como sendo a que mais gera ansiedade.

A intensidade e as qualidades afetivas da interação entre professor e alunos, segundo Machado, Frade e Falcão (2010), influenciam significativamente as crenças, sentimentos e atitudes destes em relação à Matemática. Os pesquisadores examinaram a prática de dois professores de Matemática de duas turmas de séries finais do Ensino Fundamental no que diz respeito aos valores e as correspondentes reações afetivas dos alunos sobre suas aprendizagens e desdobramentos, constatando a necessidade de melhor compreensão e consideração da influência exercida pelos valores e atitudes dos professores sobre a aprendizagem.

Magalhães e Justo (2013) delimitaram seus estudos as concepções de professoras polivalentes referentes ao uso de jogos matemáticos para a aprendizagem e sobre sua relação com a Matemática. Em pesquisa realizada a partir de atividades de formação continuada as pesquisadoras destacaram a evidência nos relatos e depoimentos de três professoras polivalentes de dificuldades e medos, em relação à Matemática, que influenciavam suas práticas. As dificuldades e medos emergem também no estudo de Oliveira, Resende e Alves (2010) quando destacam o fato de a Matemática carregar o peso de ser o "terror das disciplinas" e ter muitos alunos com dificuldades insuperáveis.

O estudo de Manfredo e Gonçalves (2012) buscou investigar saberes de professores para o ensino de Matemática nos anos iniciais da Educação Básica. Os pesquisadores, através de abordagem narrativa, concluíram que saberes referentes à Matemática e seu ensino foram sendo constituídos antes do ingresso na formação inicial para a docência, ocorrendo em meio a um conjunto de contingências e sentimentos relativos à Matemática em virtude de fatos marcantes e significativos em cada trajetória. 
Experiências vividas na infância e juventude foram destacadas como marcas que fazem evocar e valorizar aspectos diversos no que concerne à docência em Matemática.

O estudo anteriormente referido é realizado através de abordagem narrativa, o que nos leva a resgatar outros estudos nos quais as narrativas se mostraram presentes. Zuffi, Degrava, Utsumi e Prado (2014) exploraram as potencialidades das narrativas na Educação Matemática, percebendo-as como um modo de relatar, representar e refletir uma experiência. Os pesquisadores consideraram as narrativas escritas de uma professora em formação continuada e puderam perceber que o uso de tais narrativas proporcionou a esta professora uma formação continuada que levou em consideração questões culturais mais amplas, seus saberes docentes e experiências anteriores, superando, assim, as concepções de formação clássica.

Carneiro (2014) discutiu a cultura de aula de Matemática presente em narrativas, feitas por alunasprofessoras de um curso à distância de Pedagogia, sobre as lembranças relacionadas à Matemática durante a vida escolar. As escritas evidenciaram a cultura de aula de Matemática evocada por estas lembranças: aulas expositivas, memorização e aplicação de fórmulas, algoritmos e procedimentos, ênfase para os conteúdos de números e operações; relação professor-aluno perpassada por experiências positivas e negativas, professores destacados pelo gosto em ensinar, pela compreensão dos alunos, outros, pelos castigos e humilhações.

Silva e Souza (2007) apresentaram reflexões sobre como a História Oral vem sendo pensada como metodologia de pesquisa na e para a Educação Matemática, principalmente na interlocução com a História. Esta presença da utilização da História Oral como metodologia de pesquisa pode ser percebida também no trabalho de Rolkouski (2008) que buscou compreender como um professor de Matemática torna-se o professor de Matemática que é. Reforçando a presença da História Oral nos estudos selecionados, Tizzo, Flugge e Silva (2015) sinalizam a abordagem da História Oral como uma prática para auxiliar os processos formativos voltados ao futuro professor. Outra perspectiva de abordagem utilizada nos estudos são as histórias de vida. Costa e Pamplona (2009) destacaram a importância do conhecimento de histórias de vida de profissionais mais experientes como parte do processo de aprendizado do estagiário. Os pesquisadores voltam o olhar para a constituição do sujeito "professor de Matemática" explorando narrativas de vida como método de pesquisa e ensino para a formação de professores.

Tomando como objeto de estudo a "escrita de si", Nacarato (2010) analisou escritas produzidas por alunas de um curso de Pedagogia na disciplina Fundamento e Metodologia do Ensino de Matemática. A pesquisadora buscou compreender como o processo de escrita possibilita a cada uma destas acadêmicas a reinvenção de si como aprendiz de Matemática e como profissional que ensinará Matemática nos anos iniciais do ensino fundamental.

A cartografia foi outro método que adotamos na leitura dos resumos. Rodrigues (2009) utilizou o método investigativo cartográfico para acompanhar processos de subjetivação na formação inicial de professores de Matemática. Souza e Silva (2015) apresentaram articulações teóricas e práticas de uma pesquisa de doutorado que fomentou discussões acerca das possibilidades do professor de Matemática no que se refere a autonomia, ao cuidado de si. Apropriaram-se da cartografia mapeamento da subjetividade humana - buscando mapear linhas de forças que circulavam no espaço de diálogo que ocorria em encontros semanais com professores de Matemática de uma escola pública do interior de São Paulo, discutindo seus processos de subjetivação. 
A percepção em relação à Matemática foi o enfoque da pesquisa de Bretas e Ferreira (2007) que procuraram verificar como alunos do Ensino Fundamental percebem a Matemática escolar, sendo considerados, neste caso, alunos de $8^{a}$ série. Os resultados mostraram que a maioria percebe a Matemática como sendo uma disciplina de difícil aprendizagem, porém importante e útil, destacando sua aplicação no dia a dia. Para aprender Matemática os alunos consideraram ser necessário estudar mais, prestar atenção às aulas e ter mais força de vontade. Quanto aos professores acreditam que deveriam ensinar de maneira diferente, estar abertos ao diálogo, ter mais paciência e disposição para esclarecer dúvidas.

Ainda considerando estudos que são conduzidos dando relevância às percepções de estudantes do Ensino Fundamental, temos o estudo de Silva (2013) que tratou da percepção de alguns estudantes do 90 ano acerca da Matemática como conteúdo curricular. O pesquisador destacou a percepção negativa que estes estudantes têm da Matemática e ressaltou a necessidade de alterar esta percepção para que fosse possível superar dificuldades, obstáculos e incompreensões presentes no processo de aprendizagem da Matemática na sala de aula. E Ferreira (2009) que considerou além dos estudantes de $9^{a}$ ano do Ensino Fundamental, seus professores de Matemática e buscou identificar suas percepções acerca da Matemática escolar, seu ensino e aprendizagem. Os resultados encontrados, diferentemente daqueles apresentados por Silva (2013), sugeriram que a ideia que prevalece no senso comum de que a Matemática é temida e odiada por todos os alunos não representa adequadamente os participantes do estudo, já que mais da metade dos alunos afirmou gostar de Matemática ainda que reconheçam que é uma disciplina difícil de aprender. Na percepção dos alunos há relação entre gostar de Matemática e o relacionamento que é estabelecido com o professor da disciplina, porém quanto aos professores alguns nem sempre conhecem seus alunos e o que pensam sobre as aulas dessa disciplina e sobre o professor.

Ao enfocar não mais a percepção acerca da Matemática e sim do professor de Matemática, porém ainda com alunos do Ensino Fundamental, Moreira e Ferreira (2007) buscaram identificar a percepção de alunos de $8^{a}$ séries acerca do professor de Matemática, acreditando que a forma como o aluno percebe seu professor pode influenciar em seu comportamento em sala de aula, sua relação com o professor e suas atitudes diante da Matemática escolar. As pesquisadoras justificaram o estudo com base na literatura que evidencia a influência das crenças, concepções e percepções sobre o comportamento dos estudantes. As análises das respostas obtidas na pesquisa indicaram que a maioria dos alunos tem a Matemática como uma das três disciplinas preferidas e gosta do professor de Matemática, contradizendo, novamente, a crença vigente de que 'ninguém' gosta de Matemática, nem do professor de Matemática.

Já que estamos falando de gostar ou não do professor de Matemática, apresentamos aqui alguns estudos que tiveram como foco o "bom professor": Hirt e Grando (2013) analisaram a prática pedagógica do professor de Matemática, evidenciando características para o "bom professor". 0 levantamento teórico realizado pelos pesquisadores apontou algumas características esperadas do bom professor, dentre elas está a boa relação com os estudantes e domínio do conteúdo e da didática. Silva e Wrobel (2015) exploraram quais saberes são apontados pelos professores de Matemática em formação quando escrevem sobre ser um bom professor e sobre conhecimentos básicos necessários para a atuação docente. As pesquisadoras concluem que esses professores em formação percebem diferentes dimensões do Ser Professor que perpassam aspectos do saber acadêmico, do saber-fazer e do saber-subjetivo, compreendendo dentro deste saber-subjetivo aspectos das posturas dos bons 
professores. Ter uma relação professor-aluno saudável, cumplicidade, são fatores que, segundo a pesquisa, contribuem para o processo de ensino e aprendizagem.

Não mais com enfoque para o bom professor e sim para as características para uma boa aula, NagySilva, Passos e Cyrino (2010) investigaram características que alunos do curso de Pedagogia atribuem à Matemática e a uma "boa aula" de Matemática. A análise dos dados evidenciou uma Matemática vista como ferramenta, relacionada ao cotidiano e outras áreas, conhecimento que se apresenta por meio de cálculos, estudos dos números, raciocínio lógico, disciplina indefinida, cheia de mistérios, complicada. Quanto a uma "boa aula" de Matemática foram elencados aspectos como: aulas em que o professor relaciona os conceitos matemáticos e o cotidiano, aulas dinâmicas ou que utilizam materiais manipuláveis, aulas nas quais o professor ouve os alunos, é paciente, oferece ajuda, e aulas expositivas "claras".

Com a leitura dos estudos aqui apresentados é possível perceber o quanto tratar da subjetividade no que diz respeito à Educação Matemática pode ser algo bem amplo. Em nossas considerações finais, concluiremos esta análise fazendo um entrelaçamento entre os aspectos resgatados em cada trabalho e os termos elencados em nossas nuvens de palavras. Optamos por elaborar, na etapa de fechamento deste texto, uma nova organização das nuvens de palavras a fim de explicitar estas conexões que podem ser estabelecidas visando a compreensão de como os aspectos subjetivos são abordados em pesquisas na área da Educação Matemática.

\section{CONSIDERAÇÕES FINAIS}

Este é o momento de retornarmos a nossa interrogação inicial e buscar estabelecer como a subjetividade vem se mostrando nas pesquisas consideradas no corpus de análise de nosso Estado da Arte. O ser professor, os vínculos com a Matemática e as escritas de si são como fibras que permitem um entrelaçado que nos constituirá enquanto sujeitos e profissionais que trabalham com Educação Matemática.

Os termos identificados e os enfoques dados em cada escrita foram sendo distribuídos inicialmente entre os três eixos no sentido de permitir a atribuição de alguma forma de organização desta temática - subjetividade. Os trabalhos analisados permitiram adensar o que inicialmente concebíamos como possibilidades de conteúdos que pudessem compor cada um desses eixos. E desta forma neste momento da escrita optamos por resgatar as nuvens de palavras inicialmente utilizadas, porém agora agregando todos os termos a uma única nuvem que foi modificada de modo que possamos perceber linhas de conexões entre os termos (Fig. 4). Acabamos nos percebendo ao longo das leituras diante de uma rede de fios que se cruzam, rompem, unem, questionam. Na figura mantivemos a identidade com os eixos que determinamos através da permanência das cores escolhidas para a construção das nuvens de cada um, porém agora percebemos mais claramente o quanto estão permeados uns pelos outros. 


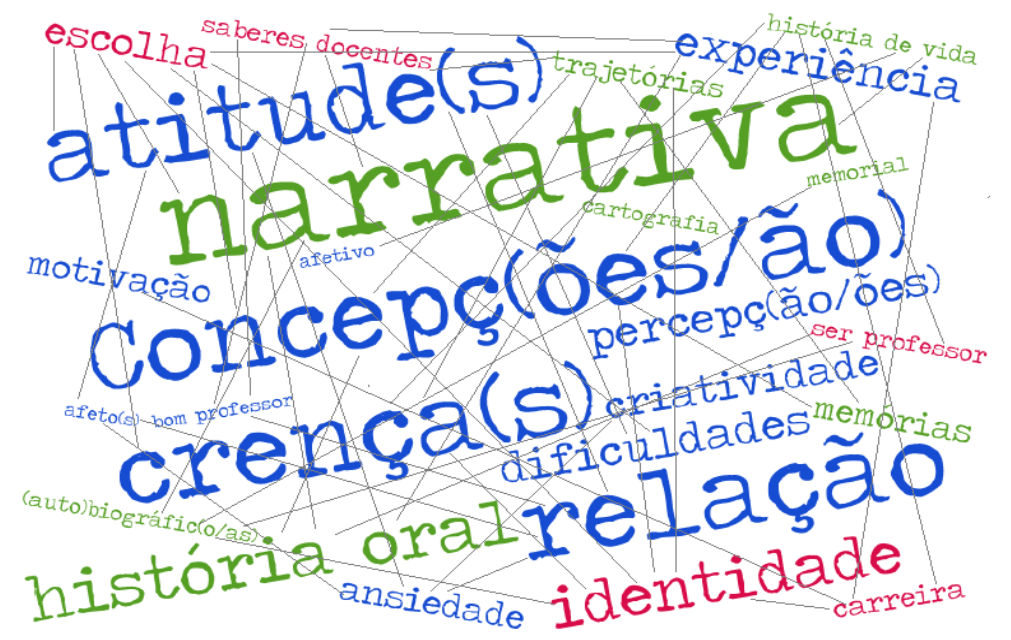

Figura 4 - Teia de palavras-chaves

Fonte: Elaborada pelos autores.

Assim, nosso estudo aponta que o ser professor atravessa tanto questões de escolha profissional, quanto questões da identidade profissional em si, o tornar-se professor, o querer ou não querer, os processos formativos que por vezes parecem tão centrados em conteúdos e metodologias, mas que se constituem como importantes espaços para repensar e redefinir aspectos da subjetividade como crenças, concepções e até medos e inseguranças. O que emerge fortemente nos trabalhos é a questão de que os processos formativos e de constituição do ser professor interagem com crenças e valores que o sujeito traz de suas vivências e trajetórias de vida.

Se em nossas análises parece que ser professor e aspectos subjetivos fundem-se, não se trata de um acaso. Desde a escolha do ser professor, a opção por este ou aquele curso, a forma como exercemos a docência, as relações estabelecidas entre professor-aluno-Matemática surgem evidências da presença de aspectos subjetivos que muitas vezes entram em conflito e ficam evidenciados quando o professor está na sua prática de sala de aula ou em situações de reflexão sobre sua prática. Falando em reflexões sobre a prática adentramos no terreno das escritas de si, cada vez mais presentes enquanto instrumentos formativos e em muitos casos reconhecidas como fonte histórica, no sentido de que as narrativas e a História Oral acabam por permitir compreensões acerca da História da Educação Matemática.

Retornando novamente às nossas interrogações iniciais... como a comunidade de pesquisadores tem atribuído importância aos aspectos subjetivos da/na relação com a Matemática? O que pode ser percebido com base na pesquisa realizada é que a comunidade de pesquisadores tem voltado o olhar para aspectos subjetivos na constituição do ser professor e na consolidação de uma identidade docente e nos vínculos que as pessoas estabelecem com a Matemática, que incluem atitudes, crenças, concepções, percepções, e tem reconhecido a importância de tais aspectos como constitutivos não só do sujeito (recorrendo ao significado do próprio termo - subjetivo), mas da profissão professor que ao lidar com diferentes sujeitos naturalmente se faz atravessar e atravessa por subjetividades. A comunidade investiga os aspectos subjetivos percorrendo o que podemos identificar como duas linhas de desenvolvimento de estudos uma pautada em questões vinculadas às identidades docentes e outra que abrange vínculos com a Matemática. Nesse sentido, as escritas de si se apresentam como metodologias de investigação dos aspectos subjetivos, que incluem as narrativas, a História Oral, as autobiografias e a cartografia dentre outras. 


\section{REFERÊNCIAS}

BERNARDO, Renata. As trajetórias escolares de alunos universitários e a interface com o trabalho docente. In: ENCONTRO NACIONAL DE EDUCAÇÃO MATEMÁTICA, 11, 2013, Curitiba, PR. Anais do... XI ENEM, 2013.

BICUDO, Maria Aparecida V. (Org.). Filosofia da educação matemática: fenomenologia, concepções, possibilidades didático-pedagógicas. São Paulo: Editora UNESP, 2010.

BOGDAN, Robert. C.; BIKLEN, Sari K. Investigação qualitativa em educação. Porto: Porto Editora, 1994.

BRETAS, Simone N. R.; FERREIRA, Ana Cristina. A percepção da Matemática escolar pelos alunos de $8^{a}$ série do Ensino Fundamental de escolas de Cachoeira do Campo. In: ENCONTRO NACIONAL DE EDUCAÇÃO MATEMÁTICA, 9, 2007, Belo Horizonte, MG. Anais do... IX ENEM, 2007.

CARNEIRO, Reginaldo Fernando. Narrativas de alunas-professoras dos Anos Iniciais do Ensino Fundamental: uma cultura de aula de Matemática. Bolema, Rio Claro, SP, v. 28, n. 49, p. 875-895, 2014.

COSTA, Shirley S.; CURI, Edda. (2010). A influência das crenças na formação inicial do professor que ensina Matemática nos Anos Iniciais. In: ENCONTRO NACIONAL DE EDUCAÇÃO MATEMÁTICA, 10, 2010, Salvador, BA. Anais do... X ENEM, 2010.

COSTA, Wanderleya. N. G.; PAMPLONA, Admur Severino. Comunidades de prática e histórias de vida: dificuldades e expectativas dos licenciandos em Matemática acerca do estágio supervisionado e do exercício da profissão docente. In: SEMINÁRIO INTERNACIONAL DE PESQUISA EM EDUCAÇÃO MATEMÁTICA, 4, 2009, Taguatinga, DF. Anais do... IV SIPEM, 2009.

CRUZ, Mara Rúbia S.; NEVES, Regina S. P. Uma análise dos afetos, das atitudes e da prática docente em Matemática, a partir das falas de estudantes do nono ano do ensino fundamental. In: ENCONTRO NACIONAL DE EDUCAÇÃO MATEMÁTICA, 10, 2010, Salvador, BA. Anais do... X ENEM, 2010.

CUNHA, Antônio Geraldo da. Dicionário etimológico da língua portuguesa. Rio de Janeiro: Lexikon, 2010.

FERREIRA, Ana Cristina. Como professores de Matemática e seus alunos do Ensino Fundamental se percebem mutuamente? dois estudos de caso. In: SEMINÁRIO INTERNACIONAL DE PESQUISA EM EDUCAÇÃO MATEMÁTICA, 4, 2009, Taguatinga, DF. Anais do... IV SIPEM, 2009.

FERREIRA, Norma S. A. As pesquisas denominadas "estado da arte". Educação \& Sociedade, 23, 79, p. 257-272, Agosto/2002.

FRADE, Cristina C.; RODRIGUES, Alexandre José. (2009). Identidades matemáticas de alunos do ensino médio da escola preparatória de cadetes do ar. In: SEMINÁRIO INTERNACIONAL DE PESQUISA EM EDUCAÇÃO MATEMÁTICA, 4, 2009, Taguatinga, DF. Anais do... IV SIPEM, 2009.

GIL, Antônio Carlos. Como elaborar projetos de pesquisa. São Paulo: Atlas, 2010.

GONTIJO, Cleyton H. Criatividade em Matemática: conceitos, metodologias e formas de avaliação. In: ENCONTRO NACIONAL DE EDUCAÇÃO MATEMÁTICA, 10, 2010, Salvador, BA. Anais do... X ENEM, 2010. 
HIRT, Cleomar Alexandre; GRANDO, Cláudia Maria. Atributos do "bom professor" de Matemática. In: ENCONTRO NACIONAL DE EDUCAÇÃO MATEMÁTICA, 11, 2013, Curitiba, PR. Anais do... XI ENEM, 2013.

LEVY, Lênio F. A constituição da identidade de professores de Matemática (em formação inicial). In: ENCONTRO NACIONAL DE EDUCAÇÃO MATEMÁTICA, 11, 2013, Curitiba, PR. Anais do... XI ENEM, 2013.

MACHADO, Milene C.; FRADE, Cristina; FALCÃO, Jorge Tarcísio R. Influência de aspectos afetivos na relação entre professor e alunos em sala de aula de Matemática. Bolema, Rio Claro, SP, v. 23, n. 36, p. 683-713, 2010.

MAGALHÃES, Jamille M. C.; JUSTO, Jutta C. R. Concepções de professores polivalentes sobre a Matemática a partir de uma formação continuada estruturada com jogos matemáticos. In: ENCONTRO NACIONAL DE EDUCAÇÃO MATEMÁTICA, 11, 2013, Curitiba, PR. Anais do... XI ENEM, 2013.

MANFREDO, Elizabeth C. G.; GONÇALVES, Tadeu O. Gênese de saberes da docência em Matemática de professores formadores. In: SEMINÁRIO INTERNACIONAL DE PESQUISA EM EDUCAÇÃO MATEMÁTICA, 5, 2012, Petrópolis, RJ. Anais do... V SIPEM, 2012.

MARQUESIN, Denise F.; NACARATO, Adair M. (2015). Minha época de escola: narrativas de futuras professoras. In: SEMINÁRIO INTERNACIONAL DE PESQUISA EM EDUCAÇÃO MATEMÁTICA, 6, 2015, Pirenópolis, GO. Anais do... VI SIPEM, 2015.

MARTINS, Rosa Maria; ROCHA, Simone A. Nos memoriais de formação: o estágio como possibilidade de desenvolvimento da constituição da identidade docente de licenciandos de Matemática. In: ENCONTRO NACIONAL DE EDUCAÇÃO MATEMÁTICA, 11, 2013, Curitiba, PR. Anais do... XI ENEM, 2013.

MENDES, Alessandra C.; CARMO, João dos S. Atribuições dadas à Matemática e ansiedade ante a Matemática: o relato de alguns estudantes do Ensino Fundamental. Bolema, Rio Claro, SP, v. 28, n. 50, p. 1368-1385, dez. 2014.

MOREIRA, Jane A.; FERREIRA, Ana Cristina. Como os alunos da $8^{a}$ série do Ensino Fundamental de Ouro Preto percebem o professor de Matemática? In: ENCONTRO NACIONAL DE EDUCAÇÃO MATEMÁTICA, 9, 2007, Belo Horizonte, MG. Anais do... IX ENEM, 2007.

NACARATO, Adair M. A formação matemática das professoras de Séries Iniciais: a escrita de si como prática de formação. Bolema, Rio Claro, SP, v. 23, n. 37, p. 905-930, 2010.

NACARATO, Adair M. O professor de matemática em início de carreira e sua constituição profissional. In: SEMINÁRIO INTERNACIONAL DE PESQUISA EM EDUCAÇÃO MATEMÁTICA, 5, 2012, Petrópolis, RJ. Anais do... V SIPEM, 2012.

NAGY-SILVA, Márcia Cristina; PASSOS, Marinez M.; CYRINO, Maria Cristina C. T. Matemática e boa aula de Matemática: algumas características na visão de futuros professores de matemática das series iniciais. In: ENCONTRO NACIONAL DE EDUCAÇÃO MATEMÁTICA, 10, 2010, Salvador, BA. Anais do... X ENEM, 2010.

OLIVEIRA, Fabiana Cristina O. S.; RESENDE, Deyse S.; ALVES, Eva Maria S. Professores de Matemática de Aracaju: suas concepções a respeito dos alunos. In: ENCONTRO NACIONAL DE EDUCAÇÃO MATEMÁTICA, 10, 2010, Salvador, BA. Anais do... X ENEM, 2010. 
PAULO, Rosa M. A constituição da identidade do professor: um olhar fenomenológico. In: SEMINÁRIO INTERNACIONAL DE PESQUISA EM EDUCAÇÃO MATEMÁTICA, 5, 2012, Petrópolis, RJ. Anais do... V SIPEM, 2012.

RODRIGUES, Carla G. Formação inicial de professores de Matemática: um estudo sobre processos de subjetivação. In: SEMINÁRIO INTERNACIONAL DE PESQUISA EM EDUCAÇÃO MATEMÁTICA, 4, 2009, Taguatinga, DF. Anais do... IV SIPEM, 2009.

ROLKOUSKI, Emerson. Histórias de vida de professores de Matemática. Bolema, Rio Claro, SP, v. 21, n. 30, p. 63-88, 2008.

SILVA, Anderson A. Narrativas de professores de Matemática sobre seus enfrentamentos cotidianos. In: ENCONTRO NACIONAL DE EDUCAÇÃO MATEMÁTICA, 11, 2013, Curitiba, PR. Anais do... XI ENEM, 2013.

SILVA, Heloisa; SOUZA, Luzia A. A História Oral na pesquisa em Educação Matemática. Bolema, Rio Claro, SP, v. 20, n. 28, p. 139-162, 2007.

SILVA, Sandra A. F.; WROBEL, Julia S. Saberes necessários aos docentes sob o olhar de professores de matemática em formação. In: SEMINÁRIO INTERNACIONAL DE PESQUISA EM EDUCAÇÃO MATEMÁTICA, 6, 2015, Pirenópolis, GO. Anais do... VI SIPEM, 2015.

SILVA, Silvia Regina V. Professor de Matemática e identidade cultural. In: ENCONTRO NACIONAL DE EDUCAÇÃO MATEMÁTICA, 9, 2007, Belo Horizonte, MG. Anais do... IX ENEM, 2007.

SILVA, Thaís L. C.; SANTOS-WAGNER, Vânia M. P. Concepções, memórias e escolha profissional de futuros professores de Matemática. In: ENCONTRO NACIONAL DE EDUCAÇÃO MATEMÁTICA, 11, 2013, Curitiba, PR. Anais do... XI ENEM, 2013.

SOUZA, Antônio Carlos C.; SILVA, Michela T. Do conceito à prática da autonomia do professor de Matemática. Bolema, Rio Claro, SP, v. 29, n. 53, p. 1309-1328, 2015.

TIZZO, Vinícius S.; FLUGGE, Flávia Cristina G.; SILVA, Heloísa da. Práticas possíveis com a História Oral na formação inicial de professores (de Matemática). Bolema, Rio Claro, SP, v. 29, n. 53, p. 887908, 2015.

ZAT, Ancilla D. A formação docente e as crenças de professores em relação à Matemática: uma rupture possível? In: ENCONTRO NACIONAL DE EDUCAÇÃO MATEMÁTICA, 11, 2013, Curitiba, PR. Anais do... XI ENEM, 2013.

ZUFFI, Edna M.; DEGRAVA, Cláudia F., UTSUMI, Miriam C.; PRADO, Esther, P. A. Narrativas na formação de professores de Matemática. O caso da professora Atíria. Bolema, Rio Claro, SP, v. 28, n. 49, p. 799-819, 2014. 